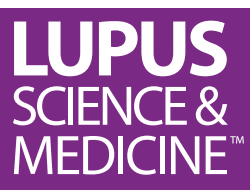

\title{
Risk factors for changes in carotid intima media thickness and plaque over 5 years in women with systemic lupus erythematosus
}

\author{
Apinya Lertratanakul, ${ }^{1}$ Julia Sun (D , ${ }^{1}$ Peggy W Wu, ${ }^{1}$ Jungwha Lee, ${ }^{2}$ Alan Dyer, ${ }^{2}$ \\ William Pearce, ${ }^{3}$ David McPherson, ${ }^{4}$ Kim Sutton-Tyrrell, ${ }^{5}$ Trina Thompson, ${ }^{6}$ \\ Emma Barinas-Mitchell, ${ }^{7}$ Rosalind Ramsey-Goldman ${ }^{1}$
}

To cite: Lertratanakul A, Sun J, Wu PW, et al. Risk factors for changes in carotid intima media thickness and plaque over 5 years in women with systemic lupus erythematosus. Lupus Science \& Medicine 2021;8:e00548. doi:10.1136/ lupus-2021-000548

KS-T deceased

Received 26 July 2021

Accepted 10 November 2021

\section{ABSTRACT}

Objective To investigate the occurrence of and risk factors for progression of carotid intima media thickness (IMT) and plaque in women with and without SLE. Methods A cohort of 149 women with SLE and 126 controls participated in SOLVABLE (Study of Lupus Vascular and Bone Long-term Endpoints). Demographics, cardiovascular and SLE factors, and laboratory assessments were collected at baseline. Carotid IMT and plaque were measured using B-mode ultrasound at baseline and at 5-year follow-up. Regression models were used to identify predictors of progression in carotid IMT and plaque; multivariate models were adjusted for age, hypertension and total cholesterol to high-density lipoprotein ratio.

Results The mean \pm SD follow-up time was $5.35 \pm 0.60$ years in cases and $5.62 \pm 0.66$ years in controls. The mean IMT change per year was $0.008 \pm 0.015 \mathrm{~mm}$ in cases and $0.005 \pm 0.019 \mathrm{~mm}$ in controls $(p=0.24)$. At followup, $31.5 \%$ of cases and $15 \%$ of controls had plaque progression, with a relative risk for plaque progression of 2.09 (95\% Cl 1.30 to 3.37). In SLE cases, higher fasting glucose and lower fibrinogen were associated with IMT progression after adjustment. Larger waist circumference and non-use of hydroxychloroquine were associated with plaque progression after adjustment.

Conclusion Potential modifiable risk factors for carotid IMT and plaque progression in women with SLE were identified, suggesting that monitoring of glucose and waist circumference and use of hydroxychloroquine may be beneficial.

\section{INTRODUCTION}

Cardiovascular disease (CVD) is a wellestablished cause of morbidity and mortality in patients with SLE and is known to occur at an earlier age than the general population. ${ }^{1-4}$ Investigations into subclinical atherosclerosis in patients with SLE have been undertaken with the hope of identifying modifiable risk factors for CVD. Earlier studies have observed increased carotid intima media thickness

\section{Key messages}

What is already known about this subject?

- Adult patients with lupus have increased subclinical atherosclerosis, as measured by carotid intima media thickness and carotid plaque, compared with healthy controls.

What does this study add?

- Higher fasting glucose and lower fibrinogen level were risk factors for progression of intima media thickness over a span of 5 years in adult women with lupus.

- Larger waist circumference and non-use of hydroxychloroquine were risk factors for plaque progression over a span of 5 years in adult women with lupus.

How might this impact on clinical practice or future developments?

- Stringent control of these modifiable risk factors may protect adult women with lupus from accelerated atherosclerosis and adverse cardiovascular events.

(IMT) and carotid atherosclerotic plaque in patients with SLE when compared with agematched and sex-matched controls. ${ }^{5-8}$ In a prospective, observational study of adult women with SLE and no previous cardiovascular events, we found baseline carotid IMT and presence of plaque to be predictive of any adverse cardiovascular events, independent of traditional cardiovascular risk factors and medication use. ${ }^{9}$

When compared with the general population, progression of atherosclerosis has been found to be accelerated in SLE. However, studies investigating risk factors for this accelerated progression are few and have yielded varied results.

Carotid IMT progression has been associated with age, ${ }^{10}$ age at diagnosis, ${ }^{11}$ longer duration of SLE, ${ }^{11} 12$ higher C3 level, ${ }^{11} 13$ 
higher homocysteine level, ${ }^{11}$ immunosuppressant use $^{13}$ and presence of nephrotic-range proteinuria ${ }^{12}$ at baseline. In contrast, Kiani $e t a l^{14}$ did not find age at diagnosis or any SLE-related factors to be significantly associated with carotid IMT progression. We have shown that women with SLE with depression have increased carotid IMT progression when compared with those without. ${ }^{15}$

Plaque progression has been associated with higher baseline homocysteine level, ${ }^{16}{ }^{17}$ longer SLE disease duration, ${ }^{14} 1617$ higher C3 level ${ }^{13}$ and immunosuppressant use. ${ }^{13}$ Only Thompson $e t a l^{13}$ found lupus activity (as measured by the Systemic Lupus Activity Measure score) to be significantly associated with plaque progression after controlling for age ${ }^{13}$ We did not find depression to be associated with plaque progression, despite the relationship with IMT progression. ${ }^{15}$ A recent study found several factors including longer baseline disease duration and higher cumulative prednisone dose to be predictive of plaque progression, but only in patients with SLE who were in low disease activity over $>50 \%$ of follow-up time. ${ }^{18}$

While previous longitudinal studies spanned 2-3 years, our study investigated progression over a longer follow-up period of 5 years to refine the identification of risk factors for carotid IMT and plaque progression in patients with SLE.

\section{METHODS}

\section{Study population}

Details of our study population have been described previously. ${ }^{19}$ Briefly, women aged $\geq 18$ years from the Chicago Lupus Database (CLD) who met at least four of the 1982 or updated 1997 American College of Rheumatology (ACR) classification criteria for SLE were invited to participate. The first 185 respondents were enrolled in SOLVABLE (Study of Lupus Vascular and Bone Longterm Endpoints). Healthy control women without SLE $(n=186)$ were recruited from the general population, matched to patients with SLE by age ( \pm 5 years), ethnicity and residence zip code from 2002 to 2009.

\section{Data collection}

All study participants provided informed consent prior to enrolment. Study participants were followed for up to 5 years over the time span from 2004 to 2013. During study visits at baseline, 36 months and 60 months, each participant provided blood and urine samples for laboratory tests, completed a self-administered questionnaire and a physician performed a physical examination. This study focuses on the study subjects who completed follow-up data obtained at 60 months.

\section{SLE-related factors}

Trained assessors collected and completed measures of lupus disease activity (Systemic Lupus Erythematosus Disease Activity Index 2000 (SLEDAI-2K) ${ }^{20}$ and damage (American College of Rheumatology Systemic Lupus International Collaborating Clinics Damage Index (ACR/SLICC-DI)), excluding coronary artery bypass grafting, myocardial infarction (MI), stroke and angina (modified ACR/SLICC-DI). Disease duration was calculated using the date the fourth ACR classification criteria for lupus ${ }^{21} 22$ was fulfilled. Self-reported information on use of corticosteroids, hydroxychloroquine (HCQ) and immunosuppressants was collected at each visit and verified in CLD; $10 \%$ of study participants were sampled and their reports were found to be $100 \%$ consistent with the medical record. Patients with SLE with active lupus nephritis were excluded at the time of enrolment. A history of lupus renal disease was defined as being present if the subject fulfilled the ACR classification criteria for lupus renal involvement (greater than $0.5 \mathrm{~g} /$ day or $3+$ proteinuria and/or presence of cellular casts) or had a renal biopsy demonstrating immune complex-mediated glomerulonephritis.

\section{Traditional cardiovascular risk factors}

Age, self-reported race/ethnicity, current smoking status and current medication use were obtained from the questionnaire. Blood pressure and waist circumference were measured twice and the mean was used for analysis.

Laboratory tests included fasting lipids, homocysteine, fasting glucose and lipoprotein(a) measured in the Lipid Laboratory at the University of Pittsburgh, Graduate School of Public Health, which has been certified by the Centers for Disease Control and Prevention; C reactive protein and fibrinogen were measured at the University of Vermont. ${ }^{19}$

Hypertension at baseline was defined a priori as present if systolic blood pressure was $\geq 140 \mathrm{~mm} \mathrm{Hg}$ or diastolic blood pressure was $\geq 90 \mathrm{~mm} \mathrm{Hg}$ or if on an antihypertensive medication excluding use solely for renal disease. The total cholesterol to high-density lipoprotein (HDL) ratio was calculated. Presence of diabetes was determined if the fasting glucose level was $\geq 126 \mathrm{mg} / \mathrm{dL}$, if the patient was currently taking diabetes medication or if the patient self-reported diabetes.

\section{Imaging and subclinical CVD outcome measures}

Study participants underwent assessment for carotid IMT and plaque with carotid ultrasounds at baseline and at 60-month follow-up. Carotid ultrasounds were obtained by technicians who received training at the University of Pittsburgh using B-mode ultrasound. All baseline and 5-year follow-up carotid ultrasound readings were performed at the University of Pittsburgh Ultrasound Research Laboratory by radiologists who followed strict protocols. Ultrasound images were read in a blinded fashion. The reproducibility of carotid duplex scanning using this technique has been previously documented..$^{23} 24$ Ultrasound technicians were blinded to subjects' SLE/ control status.

Carotid IMT was measured across eight sites, including the bilateral near and distal walls of the common carotid artery, the distal wall of the carotid bulb, and the internal carotid artery. Average carotid IMT was obtained from these eight measurements. Difference in the mean of 
IMT readings at baseline and follow-up was divided by the follow-up time in years to give a change per year, which was used for analysis.

Carotid plaque was assessed across eight sites, including the bilateral common carotid artery, carotid bulb, external carotid artery and proximal internal carotid artery. Plaque was defined as a focal, protruding area that was $\geq 50 \%$ greater than the thickness of the adjacent intima media layer. The degree of plaque at each site was graded between 0 (no observable plaque) and 3 (plaque covering $\geq 50 \%$ of the vessel diameter). The sum of the grades from each of the eight sites was the plaque index. Plaque progression was defined as any increase in plaque index at 60-month follow-up visit. Plaque regression was defined as any decrease in plaque index at 60-month follow-up visit. Plaque index score that remained the same at the time of follow-up was defined as no change.

\section{Statistical methods}

Patient demographic data, laboratory values and subclinical CVD measures were described as mean, SD and percentages. IMT progression was analysed as a continuous variable and defined as the difference in IMT between follow-up and at baseline visit. Change in IMT was normally distributed. Plaque progression was analysed as a dichotomous variable (present/abnormal vs absent/ normal).

Linear and logistic regression models were used to estimate the relationships of progression of IMT and plaque, respectively, with the various baseline cardiovascular risk factors in SLE cases. These models were further adjusted for age, total cholesterol to HDL ratio and presence of hypertension. Smoking status and diabetes were not included in the adjustment covariates due to too few cases self-identified as current smokers or defined as diabetic. Time to follow-up was not significantly correlated with progression measures and was thus not included.

Linear regression results were reported as $\beta$-coefficient with $95 \%$ CI. $\beta$-coefficients represented annual change in IMT for 1 SD difference for a continuous risk factor. Logistic regression results were reported as OR with 95\% CI.

A second analysis was done using combined data from cases and controls in which the presence of SLE was univariately regressed against the progression variables as an independent variable. This model was also adjusted for age, total cholesterol to HDL ratio and presence of hypertension.

Of the 149 SLE cases, 12 had prior CVD events (MI, percutaneous transluminal coronary angioplasty, angina, coronary artery bypass graft, cerebrovascular accident or transient ischaemic attack) confirmed on chart review. A sensitivity analysis was performed excluding SLE cases with prior CVD events. We did not observe any significant difference in regression results; therefore, the results presented here include SLE cases with prior CVD events.

All data analyses were performed using SAS V.9.4 software.
RESULTS

Of the 185 women with SLE enrolled, 36 did not have a follow-up visit (20 refused participation, 3 did not respond, 2 were unable to be reached, 2 relocated and 9 were deceased). Of the nine deceased patients with SLE, the cause of death was known in five: two died from heart failure, one died from lung cancer, one died from unknown cancer and one died from infectious complications. SLE cases lost to follow-up had a higher rate of smoking, End stage renal disease (ESRD) and corticosteroid use at baseline compared with the SLE cases included in this study (data not shown).

Of the 186 controls enrolled, 60 did not have a follow-up visit (one died from unknown cancer and the remainder refused participation or could not be reached). The lost to follow-up controls had higher baseline glomerular filtration rate (GFR) and a higher percentage of African Americans and Asians compared with the controls included in this study (data not shown).

A total of 149 SLE cases and 126 controls were included in the subsequent analyses. The mean \pm SD time to follow-up was $5.35 \pm 0.60$ years in cases and $5.62 \pm 0.66$ years in controls.

\section{Demographics and traditional cardiovascular risk factors}

The mean \pm SD age at first study visit was $43.2 \pm 10.1$ years in cases and $46.6 \pm 10.0$ years in controls $(\mathrm{p}=0.006$; table 1$)$. Most were Caucasian, with a small percentage of current smokers at baseline. More SLE cases were noted to have hypertension compared with controls $(52.3 \%$ vs $23.8 \%$, $\mathrm{p}<0.001)$. Fasting glucose levels in SLE cases were $91.0 \pm 18.5 \mathrm{mg} / \mathrm{dL}$ compared with $96.8 \pm 18.5 \mathrm{mg} / \mathrm{dL}$ in controls $(\mathrm{p}=0.01)$. Homocysteine level in SLE cases was higher than that found in controls $(11.2 \pm 4$.1 vs $8.6 \pm 2.6$, $\mathrm{p}<0.001)$. In cases, the mean total cholesterol to HDL ratio was $3.7 \pm 1.4$, with $7.4 \%$ taking statin medication and $20.8 \%$ taking aspirin. In controls, the mean total cholesterol to $\mathrm{HDL}$ ratio was $3.5 \pm 1.0$, with $4.8 \%$ taking statin and less were taking aspirin $(7.1 \%)$ compared with cases $(\mathrm{p}=0.001)$. GFR was not significantly different between cases and controls $(\mathrm{p}=0.89)$.

\section{SLE factors}

At baseline visit, the mean \pm SD SLEDAI-2K and modified

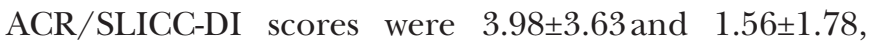
respectively (table 1 ). The median modified ACR/ SLICC-DI score was 1.0 with an IQR of 2.0. The average disease duration was 12.0 \pm 8.6years. Anti-double stranded DNA (dsDNA) antibody by the Crithidia luciliae method was present in $49 \%$ (positive result was $\geq 1: 10$ titres), with a mean titre of $87.5 \pm 182.8$ at baseline.

Of SLE cases, $37.6 \%$ were taking corticosteroids at baseline, with a mean $\pm \mathrm{SD}$ corticosteroid dose of 12.1 \pm 8.7 . Baseline daily corticosteroid dose was not significantly different in those with fasting glucose levels $\geq 100 \mathrm{mg} / \mathrm{dL}$ when compared with those with fasting glucose levels $<100 \mathrm{mg} / \mathrm{dL} \quad(\mathrm{p}=0.44$; data not shown). Of the cases $75 \%$ were taking HCQ and $35.6 \%$ 
Table 1 Baseline demographics of SLE cases and controls

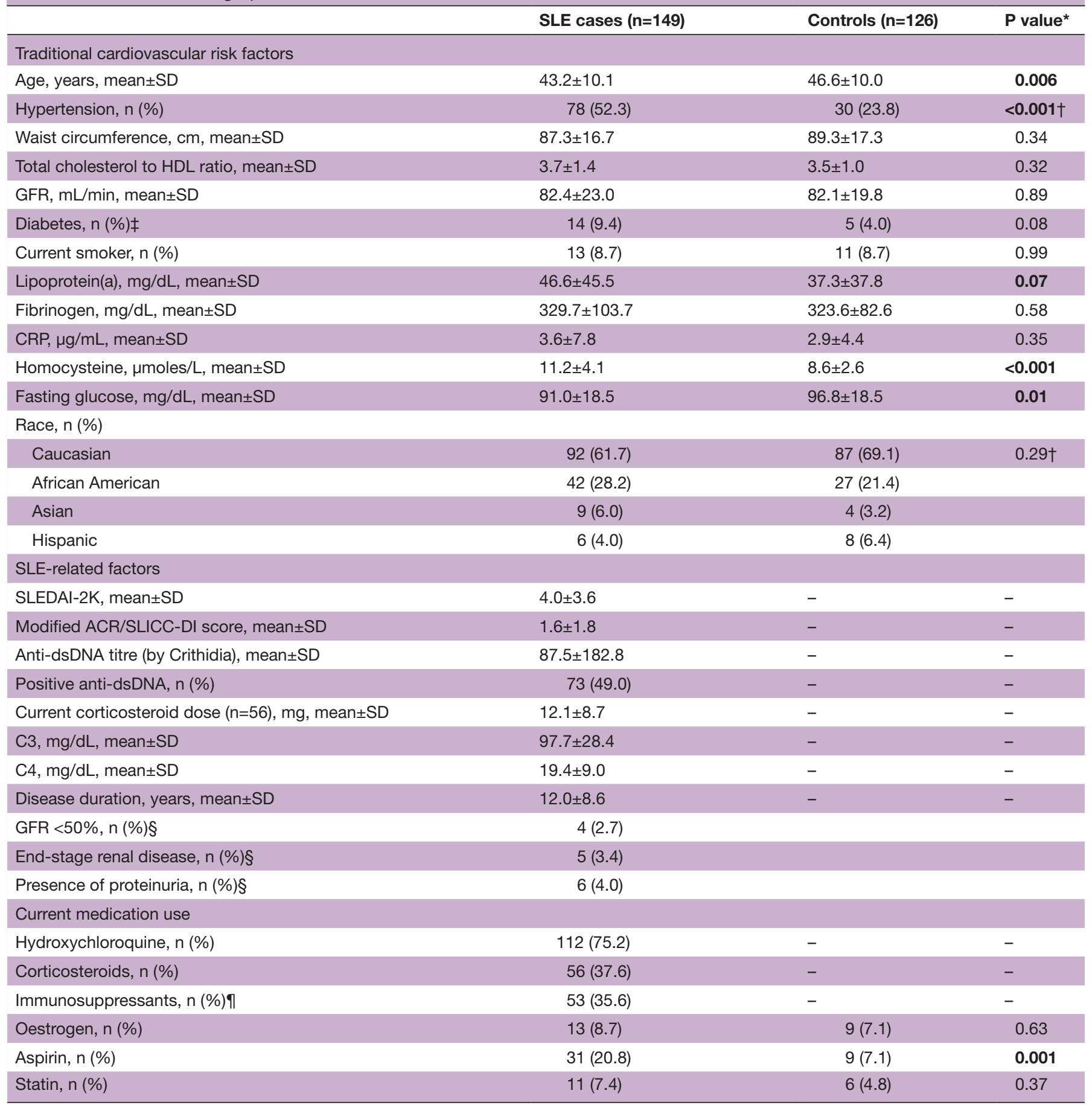

Modified ACR/SLICC-DI excluding coronary artery bypass grafting, myocardial infarction, stroke and angina.

*Two-sided t-test used for continuous variables and Fisher's exact test for proportions.

$+\chi^{2}$ test used.

†Fasting glucose $\geq 126 \mathrm{mg} / \mathrm{dL}$ or on diabetes medication or self-reported diabetes.

§Defined by ACR/SLICC-DI components.

ๆCyclophosphamide, azathioprine, methotrexate, mycophenolate mofetil, ciclosporin or tacrolimus.

ACR/SLICC-DI, American College of Rheumatology Systemic Lupus International Collaborating Clinics Damage Index; CRP, C reactive protein; GFR,

Glomerular filtration rate; HDL, high-density lipoprotein; SLEDAI-2K, Systemic Lupus Erythematosus Disease Activity Index 2000.

taking immunosuppressants: $5 \quad(3.4 \%)$ were taking cyclophosphamide, $9(6.0 \%)$ azathioprine, $17(11.4 \%)$ methotrexate, $24(16.1 \%)$ mycophenolate, $5(3.4 \%)$ ciclosporin and $1(0.67 \%)$ tacrolimus.
Four $(2.7 \%)$ cases had GFR $<50 \%$ at baseline, five $(3.4 \%)$ were in end-stage renal disease and six $(4.0 \%)$ had proteinuria by the ACR/SLICC-DI criteria. 
Table 2 Carotid intima media thickness, mm (mean \pm SD) or $n(\%)$

\begin{tabular}{llll}
\hline & Cases $(\mathbf{n}=149)$ & Controls $(\mathbf{n}=126)$ & $P$ value \\
\hline Baseline & $0.606 \pm 0.129$ & $0.632 \pm 0.129$ & 0.10 \\
5-year follow-up & $0.644 \pm 0.120$ & $0.657 \pm 0.134$ & 0.39 \\
Change per year & $0.008 \pm 0.015$ & $0.005 \pm 0.020$ & 0.24 \\
Any increase at 5-year follow-up & $108(72.5)$ & $84(66.7)$ & 0.36 \\
Regression at 5-year follow-up & $41(27.5)$ & $42(33.3)$ & 0.30 \\
\hline
\end{tabular}

\section{CVD events}

CVD events were documented throughout the 5-year period of this study. We confirmed these CVD events using participants' medical records. Seven SLE cases experienced at least one CVD event during the 5-year period. Two out of the seven SLE cases experienced two separate CVD events, while five out of the seven SLE cases experienced one CVD event. The nine CVD events reported in SLE cases included one angina, one MI, two strokes, two percutaneous transluminal coronary angioplasties and three transient ischaemic attacks. One control participant experienced one angina event during the 5 -year period.

\section{Imaging markers}

Baseline

The mean IMT at baseline was $0.61 \pm 0.13 \mathrm{~mm}$ in cases and $0.63 \pm 0.13$ in controls $(p=0.1)$. The mean IMT at follow-up was $0.64 \pm 0.12 \mathrm{~mm}$ in cases and $0.66 \pm 0.13 \mathrm{~mm}$ in controls $(\mathrm{p}=0.39)$ (table 2$)$. Fifty-five $(36.9 \%)$ cases and $51(40.5 \%)$ controls had plaque at baseline $(\mathrm{p}=0.72)$.

\section{Follow-up}

The mean IMT change per year ( $\triangle \mathrm{IMTpy}$ ) was $0.008 \pm 0.015 \mathrm{~mm}$ in cases and $0.005 \pm 0.019 \mathrm{~mm}$ in controls $(\mathrm{p}=0.24)$ (table 2$)$. Of the 149 cases, $108(72.5 \%)$ had any increase in IMT, and of 126 controls $84(66.7 \%)$ had any increase in IMT at follow-up $(\mathrm{p}=0.36)$. Forty-one $(27.5 \%)$ cases and $42(33.3 \%)$ controls had regression in IMT at follow-up $(\mathrm{p}=0.30)$.

At follow-up, $31.5 \%$ of cases and $15 \%$ of controls had plaque progression, with a relative risk (RR) for plaque progression of 2.09 (95\% CI 1.30 to 3.37) (table 3). Of those with plaque at baseline, $24(16.1 \%)$ cases and 10 $(7.9 \%)$ controls developed more plaque at follow-up $(\mathrm{p}=0.04)$, while $16(10.7 \%)$ cases and $26(20.6 \%)$ controls had less plaque at follow-up than at baseline $(\mathrm{p}=0.04)$.
Twenty-three (15.4\%) cases and nine (7.1\%) controls had no plaque at baseline and developed new plaque at follow-up ( $\mathrm{RR}=2.16,95 \% \mathrm{CI} 1.04$ to 4.50$)$. The cases and controls that had plaque at baseline were more likely to have progressed at follow-up than those without plaque at baseline $(16.1 \%$ vs $15.4 \%$ in cases, $7.9 \%$ vs $7.1 \%$ in controls).

\section{Analysis of progression risk factors in SLE cases IMT progression in SLE}

Baseline risk factor associations with 5-year $\Delta$ IMTpy regression results for cases are shown in table 4 . In univariate models, increased baseline fasting glucose and SLEDAI-2K score were associated with increase in IMTpy. After adjustment for age, hypertension and cholesterol to HDL ratio, SLEDAI-2K score was no longer associated and lower fibrinogen level became associated. No renal or SLE factors were significantly associated with $\Delta \mathrm{IMTpy}$.

\section{Plaque progression in SLE}

The 5-year follow-up of plaque progression regression results is shown in table 5 . In univariate models, plaque progression was associated with older age, presence of hypertension, larger waist circumference, higher fasting glucose, higher fibrinogen level, longer disease duration and non-use of HCQ. In multivariate models, after adjusting for age, hypertension and cholesterol to HDL ratio, greater waist circumference and non-use of HCQ remained associated.

\section{Combined analysis for SLE as progression risk factor}

In the combined analysis of cases and controls, the presence of SLE was not significantly associated with $\triangle \mathrm{IMTpy}$ $(\beta=132.2$, 95\% CI -90.2 to 354.7$)$. As depression in women with SLE has been shown to be a risk factor for IMT progression, ${ }^{15}$ models were additionally adjusted for

Table 3 Carotid plaque progression categories at 5-year follow-up

\begin{tabular}{|c|c|c|c|c|c|c|}
\hline & $\begin{array}{l}\text { No plaque } \\
\text { and no } \\
\text { change, n (\%) }\end{array}$ & $\begin{array}{l}\text { No plaque and } \\
\text { progressed, n (\%) }\end{array}$ & $\begin{array}{l}\text { Plaque and } \\
\text { regressed, n (\%) }\end{array}$ & $\begin{array}{l}\text { Plaque and } \\
\text { no change, n } \\
(\%)\end{array}$ & $\begin{array}{l}\text { Plaque and } \\
\text { progressed, n (\%) }\end{array}$ & $\begin{array}{l}\text { Relative risk } \\
\text { of progression } \\
(95 \% \mathrm{Cl})\end{array}$ \\
\hline $\begin{array}{l}\text { Controls } \\
(n=126)\end{array}$ & $66(52.4)$ & $9(7.1)$ & $26(20.6) \dagger$ & 15 (11.9) & $10(7.9)$ & \\
\hline
\end{tabular}

Relative risk was calculated as the proportion of cases who progressed compared with the proportion of controls who progressed.

${ }^{*} n=11$ regressed to normal, $n=5$ regressed but were still abnormal.

$\dagger \mathrm{n}=16$ regressed to normal, $\mathrm{n}=10$ regressed but were still abnormal. 
Table 4 Association of intima media thickness progression at 5-year follow-up* and baseline cardiovascular risk factors in cases

\begin{tabular}{|c|c|c|c|c|}
\hline & \multicolumn{2}{|l|}{ Unadjusted } & \multicolumn{2}{|l|}{ Adjusted† } \\
\hline & $\beta \mp\left(\times 10^{-4} \mathrm{~mm} /\right.$ year $)$ & $95 \% \mathrm{Cl}\left(\times 10^{-4} \mathrm{~mm} /\right.$ year $)$ & $\beta \ddagger\left(\times 10^{-4} \mathrm{~mm} /\right.$ year $)$ & $95 \% \mathrm{Cl}\left(\times 10^{-4} \mathrm{~mm} /\right.$ year $)$ \\
\hline \multicolumn{5}{|l|}{ Traditional risk factors } \\
\hline Hypertension, yes/no & -82.4 & -329.1 to 164.3 & - & - \\
\hline $\begin{array}{l}\text { Total cholesterol to high-density } \\
\text { lipoprotein ratio }\end{array}$ & 29.1 & -32.5 to 90.6 & - & - \\
\hline Current smoking status, yes/no & -382.6 & -815.4 to 50.2 & -369.2 & -808.1 to 69.7 \\
\hline Fasting glucose, mg/dL & 0.4991 & 0.1461 to $0.8520 \S$ & 0.5475 & 0.1825 to $0.9124 \S$ \\
\hline Waist circumference, $\mathrm{cm}$ & 0.3597 & -0.0246 to 7.440 & 0.3996 & -0.0293 to 0.8286 \\
\hline Fibrinogen, mg/dL & 0.0512 & -0.1025 to 0.0002 & -0.0634 & -0.1196 to -0.0072 \\
\hline Modified ACR/SLICC-DI & -6.9459 & -35.1 to 21.2 & -8.8293 & -40.0 to 22.3 \\
\hline SLEDAI-2K & 12.9 & 0.0583 to 25.7 & 11.7 & -1.9798 to 25.3 \\
\hline Disease duration, years & -0.2510 & -1.9210 to 1.4191 & 0.0456 & -1.7016 to 1.7928 \\
\hline $\mathrm{C} 3, \mathrm{mg} / \mathrm{dL}$ & 0.0431 & -0.1082 to 0.1944 & 0.0526 & -0.1134 to 0.2186 \\
\hline $\mathrm{C} 4, \mathrm{mg} / \mathrm{dL}$ & -1.0103 & -2.5722 to 0.5515 & -1.1131 & -2.8064 to 0.5803 \\
\hline Corticosteroid dose, mg & -0.0740 & -1.854 to 1.706 & -0.1526 & -1.9703 to 1.6650 \\
\hline Anti-dsDNA level & 0.000338 & -0.00337 to 0.00404 & 0.000231 & -0.0035 to 0.0004 \\
\hline GFR $<50 \%$, yes/no & -552.3 & -1310.4 to 205.8 & -575.4 & -1346.0 to 196.1 \\
\hline ESRD, yes/no & -56.0 & -603.3 to 491.4 & -127.4 & -691.5 to 436.8 \\
\hline Aspirin & -33.4 & -337.3 to 270.6 & -46.6 & -353.0 to 259.8 \\
\hline Corticosteroid & -11.4 & -264.5 to 24.7 & -56.4 & -320.1 to 207.3 \\
\hline Immunosuppressant & -154.9 & -411.4 to 101.6 & -210.7 & -486.4 to 65.0 \\
\hline
\end{tabular}

Modified ACR/SLICC-DI excluding coronary artery bypass grafting, myocardial infarction, stroke and angina.

${ }^{*}$ Change from baseline to 5 years.

†Adjusted for age, total cholesterol to high-density lipoprotein ratio and presence of hypertension.

$\ddagger \beta$-coefficient calculated for a 1 SD increase in risk factor for continuous variables.

$\S$ Statistically significant at $p<0.05$.

ПCyclophosphamide, azathioprine, methotrexate, mycophenolate mofetil, ciclosporin or tacrolimus.

ACR/SLICC-DI, American College of Rheumatology Systemic Lupus International Collaborating Clinics Damage Index; Anti-dsDNA, Anti-double stranded DNA; CRP, C reactive protein; ESRD, End stage renal disease; GFR, Glomerular filtration rate; SLEDAl-2K, Systemic Lupus Erythematosus Disease Activity Index 2000.

the presence of depression; this did not abrogate the association with any of the risk factors.

In the combined analysis of cases and controls, those with SLE were more likely to have plaque progression when compared with controls in both unadjusted $(\mathrm{OR}=2.60,95 \% \mathrm{CI} 1.43$ to 4.72$)$ and adjusted $(\mathrm{OR}=2.93$, $95 \%$ CI 1.49 to 5.74) models. The regression models were additionally adjusted for the presence of depression; associations were not altered.

\section{DISCUSSION}

In this 5-year follow-up study, we found that among SLE cases, higher fasting glucose and lower fibrinogen were independent predictors of carotid IMT progression; large waist circumference and non-use of HCQ were independent predictors of plaque progression. SLE was an independent risk factor for carotid plaque progression, but not for carotid IMT progression. 
Table 5 Association of plaque progression at 5-year follow-up* and baseline cardiovascular risk factors in cases

\begin{tabular}{|c|c|c|c|c|}
\hline & \multicolumn{2}{|c|}{ Unadjusted } & \multicolumn{2}{|c|}{ Adjusted $†$} \\
\hline & OR‡ & $95 \% \mathrm{Cl}$ & OR & $95 \% \mathrm{Cl}$ \\
\hline \multicolumn{5}{|l|}{ Traditional risk factors } \\
\hline Age, years & 2.01 & 1.37 to $2.97 \S$ & - & - \\
\hline Hypertension, yes/no & 2.60 & 1.26 to $5.37 \S$ & - & - \\
\hline Total cholesterol to high-density lipoprotein ratio & 1.28 & 0.91 to 1.80 & - & - \\
\hline Lipoprotein(a), mg/dL & 1.23 & 0.88 to 1.72 & 1.12 & 0.77 to 1.63 \\
\hline Waist circumference, $\mathrm{cm}$ & 1.79 & 1.25 to $2.57 \S$ & 1.62 & 1.07 to $2.45 \S$ \\
\hline Current smoking status, yes/no & 2.80 & 0.89 to 8.85 & 2.09 & 0.63 to 6.89 \\
\hline Fasting glucose, $\mathrm{mg} / \mathrm{dL}$ & 2.11 & 1.22 to $3.64 \S$ & 1.63 & 0.96 to 2.74 \\
\hline Fibrinogen, mg/dL & 1.62 & 1.13 to $2.31 \S$ & 1.42 & 0.95 to 2.14 \\
\hline $\mathrm{GFR}, \mathrm{mL} / \mathrm{min}$ & 0.71 & 0.50 to 1.02 & 1.04 & 0.68 to 1.59 \\
\hline Homocysteine, $\mathrm{mg} / \mathrm{dL}$ & 1.30 & 0.93 to 1.82 & 1.07 & 0.74 to 1.56 \\
\hline \multicolumn{5}{|l|}{ SLE-related factors } \\
\hline Modified ACR/SLICC-DI & 1.33 & 0.94 to 1.87 & 1.09 & 0.72 to 1.63 \\
\hline SLEDAI-2K & 1.08 & 0.79 to 1.47 & 1.19 & 0.83 to 1.70 \\
\hline Disease duration, years & 1.57 & 1.11 to $2.22 \S$ & 1.45 & 0.99 to 2.12 \\
\hline $\mathrm{C} 3, \mathrm{mg} / \mathrm{dL}$ & 1.34 & 0.94 to 1.90 & 1.02 & 0.68 to 1.53 \\
\hline $\mathrm{C} 4, \mathrm{mg} / \mathrm{dL}$ & 1.32 & 0.93 to 1.87 & 1.01 & 0.68 to 1.49 \\
\hline Corticosteroid dose, mg & 1.21 & 0.70 to 2.09 & 1.25 & 0.64 to 2.41 \\
\hline Anti-dsDNA level & 0.85 & 0.57 to 1.27 & 0.82 & 0.54 to 1.23 \\
\hline GFR $<50 \%$, yes/no & 2.22 & 0.30 to 16.28 & 1.72 & 0.22 to 13.27 \\
\hline ESRD, yes/no & 3.41 & 0.55 to 21.13 & 5.11 & 0.77 to 33.88 \\
\hline Proteinuria, yes/no & 1.09 & 0.19 to 6.17 & 1.17 & 0.18 to 7.63 \\
\hline \multicolumn{5}{|l|}{ Current medication use, yes vs no } \\
\hline Hydroxychloroquine & 0.43 & 0.20 to $0.93 \S$ & 0.38 & 0.16 to $0.90 \S$ \\
\hline Oestrogen & 2.80 & 0.89 to 8.85 & 1.95 & 0.57 to 6.71 \\
\hline Statin & 1.91 & 0.55 to 6.59 & 1.23 & 0.30 to 5.00 \\
\hline Aspirin & 1.04 & 0.45 to 2.43 & 0.94 & 0.37 to 2.38 \\
\hline Corticosteroid & 1.25 & 0.62 to 2.52 & 1.74 & 0.77 to 3.93 \\
\hline Immunosuppressant & 1.19 & 0.58 to 2.43 & 1.14 & 0.50 to 2.60 \\
\hline
\end{tabular}

Modified ACR/SLICC-DI excluding coronary artery bypass grafting, myocardial infarction, stroke and angina.

${ }^{*}$ Change from baseline to 5 years.

†Adjusted for age, total cholesterol to high-density lipoprotein ratio and presence of hypertension.

¥OR calculated for a $1 \mathrm{SD}$ increase in risk factor for continuous variables.

$\S$ Statistically significant at $p<0.05$.

ПCyclophosphamide, azathioprine, methotrexate, mycophenolate mofetil, ciclosporin or tacrolimus.

ACR/SLICC-DI, American College of Rheumatology Systemic Lupus International Collaborating Clinics Damage Index; Anti-dsDNA, Antidouble stranded DNA; ESRD, End stage renal disease; GFR, Glomerular filtration rate; SLEDAI-2K, Systemic Lupus Erythematosus Disease Activity Index 2000.

At baseline, plaque was present in $37 \%$ of cases, which is consistent with previous reports. ${ }^{6}{ }^{8}$ Other investigators $^{725}$ noted less frequent occurrence of plaque at $23 \%$ and $17 \%$. However, one cohort was slightly younger than ours $(38 \pm 12 \text { years vs } 43.2 \pm 10.1 \text { years })^{7}$ and the other used an alternate definition of plaque (IMT $\geq 1.3 \mathrm{~mm}$ ) ${ }^{25} \mathrm{We}$ observe plaque in $40 \%$ of controls at baseline. The prevalence of carotid plaque in the general population has ranged from $17 \%$ reported by Thompson et al $l^{13}$ to $31 \%$ reported by Ajeganova $e t$ al in a recent study ${ }^{26}$ and up to $54 \%$ among healthy, postmenopausal women reported by Sutton-Tyrrell et al. ${ }^{27}$

IMT values in our population at baseline and at follow-up could be considered normal, although definitions of abnormal IMT are variable in the literature. In the general population, abnormal/atherosclerotic IMT has been considered $>0.83 \mathrm{~mm},{ }^{28}$ with $>1.0 \mathrm{~mm}$ suggestive of plaque, ${ }^{29}$ whereas in some SLE studies a thickened IMT 
is considered to be $>0.9 \mathrm{~mm}$ and plaque defined to be $>1.3 \mathrm{~mm} .{ }^{25}$ The mean IMT in the general population has been reported from $0.66 \pm 0.13 \mathrm{~mm}$ to $0.92 \pm 0.16 \mathrm{~mm},{ }^{29-31}$ which is higher than our baseline or follow-up (table 2); some SLE studies have reported lower IMT levels in SLE versus controls, ${ }^{82}$ while others have noted no difference between those with SLE and controls. ${ }^{13}$ It is possible that arterial remodelling occurred prior to baseline in response to atherosclerosis and thus a significant progression was not captured over the follow-up period.

At follow-up, $\Delta$ IMTpy had not significantly increased with an average of $0.007 \mathrm{~mm}$, which is less than the noted annual $0.01-0.015 \mathrm{~mm}$ increase associated with ageing in the general population. ${ }^{33}$ Our progression rate was also less than that reported by de Leeuw et al $l^{10}$ of $0.012 \pm 0.04 \mathrm{~mm} /$ year. This may be related to the number of patients with IMT regression in our cohort. Better control of disease activity and more judicious use of glucocorticoids in patients with lupus as well as improvement in the prevention and treatment of established modifiable cardiovascular risk factors in the modern era in patients with lupus and the general population are possible contributing factors to carotid IMT and plaque regression.

Although SLE itself was found to be an independent risk factor in plaque progression, we did not find disease damage to be associated with plaque ${ }^{1317}$ or IMT progres$\operatorname{sion}^{511} 13$ after adjustment for age, hypertension and cholesterol to HDL ratio, consistent with previous studies. Similar to other studies, baseline disease activity was not associated with plaque progression ${ }^{81012} 14$ but was associated with progression in IMT in unadjusted models. However, after adjustment for cardiovascular risk factors, the association disappeared. How risk factors associated with active SLE disease interact with traditional cardiovascular markers in the atherosclerosis process remains to be better understood.

Our results suggest HCQ use to be protective against carotid plaque progression, but not against IMT progression. Observational studies on the effect of HCQ in atherosclerosis in patients with SLE have yielded varied results but overall suggest a protective effect against accelerated atherosclerosis. ${ }^{33} 34$ Roman $e t a l^{8}$ found a borderline independent effect of current or former treatment with HCQ in reducing plaque burden in patients with SLE. HCQ use has also been observed to result in lower aortic stiffness ${ }^{35}$ and lower systemic vascular resistance ${ }^{36}$ suggesting a more systemic effect on the cardiovascular system. HCQ use has also been observed to decrease subclinical atherosclerosis in patients with SLE by reducing the amount of circulating proatherogenic effector $\mathrm{T}$ cell subsets. ${ }^{37}$

Higher fasting glucose levels were associated with IMT progression in the adjusted models, and a greater waist circumference was associated with plaque progression. These risk factors may indicate the presence of metabolic syndrome, which may be a risk factor in the development of IMT and atherosclerosis in SLE. ${ }^{38}$ Waist circumference is a known risk factor for insulin resistance. Indexes of insulin resistance are higher in non-diabetic patients with SLE compared with controls and are associated with carotid plaques and IMT thickness. ${ }^{39}$ Of note, we did not find corticosteroid doses to be different between those with fasting glucose levels $\geq 100 \mathrm{mg} / \mathrm{dL}$ and those with lower fasting glucose levels (data not shown).

The reason for the association between lower fibrinogen levels and IMT progression is not clear. Fibrinogen is known to be directly involved in atherogenesis and in inflammation. ${ }^{40}$ In the Coronary Artery Risk Development in Young Adults study of 1396 adults aged 25-37years, elevated fibrinogen levels were associated with IMT progression after a 13-year follow-up. ${ }^{40}$ This surprising finding needs to be further investigated.

While others have found an association between IMT progression and nephrotic-range proteinuria and immunosuppressant use, ${ }^{10} 121316$ we did not find such associations in our cohort. First, our cohort had few numbers with proteinuria, and in those with GFR $<50 \%$ and ESRD there was no association with IMT progression in univariate nor adjusted models and no association with plaque progression in a univariate model.

There are recognised limitations to this study. This is a small cohort of subjects, with approximately $19 \%$ of enrolled cases without 5-year follow-up data. We had too few numbers identified as current smokers and as patients with diabetes and did not control for these known cardiovascular risk factors. The number of subjects with significant renal impairment at baseline was small and stable adjusted model estimates could not be obtained. Of the 185 patients with SLE who enrolled in this study, 38.9\% fulfilled the ACR criteria for lupus renal involvement or had a renal biopsy demonstrating immune complexmediated glomerulonephritis. This suggests that majority of patients with SLE who had renal involvement likely had more active renal disease earlier on in their disease course and had achieved remission by the time they enrolled in this study. Our follow-up time may not have been sufficient for distinct changes in IMT or plaque to occur. Our ultrasound methods used traditional B-mode two-dimensional ultrasound to detect plaque; threedimensional ultrasound is a newer imaging method that may detect more subtle findings suggesting vulnerable plaque and change in plaque more reliably by measuring plaque volume. ${ }^{41}{ }^{42}$ It is possible that alterations and fluctuations of risk factors over time may affect the progression of subclinical atherosclerosis and may be a reason for why previous studies on risk factors for accelerated atherosclerosis in SLE have yielded differing results. An inception cohort of patients newly diagnosed with SLE (within the past 15 months) exemplifies a reasonable study approach to include a more uniform group of patients with SLE to identify risk factors for the development of metabolic syndrome and atherosclerosis over time. ${ }^{43}$ IMT progression has also been described to be site-specific in association with various risk factors, ${ }^{44}{ }^{45}$ and as the IMT measurements were averaged across eight sites a segmentspecific progression may not have been apparent. 


\section{CONCLUSION}

We identified SLE as an independent risk factor for carotid plaque progression. Fasting glucose and lower fibrinogen predicted carotid IMT progression, while waist circumference and non-use of HCQ predicted plaque progression. These are potentially modifiable risk factors for subclinical atherosclerosis in patients with SLE that warrant attention and stringent control. While better screening for these risk factors and earlier implementation of lifestyle modifications are essential, future research is needed to examine the longitudinal efficacy and safety of interventions including HCQ use in alleviating metabolic syndrome and the progression of atherosclerosis in patients with SLE. The implementation of an inception cohort may be a reasonable study approach to begin to answer these questions.

\section{Author affiliations}

${ }^{1}$ Rheumatology, Northwestern University Feinberg School of Medicine, Chicago, Illinois, USA

${ }^{2}$ Preventive Medicine, Northwestern University Feinberg School of Medicine, Chicago, Illinois, USA

${ }^{3}$ Surgery, Northwestern University Feinberg School of Medicine, Chicago, Illinois, USA

${ }^{4}$ Cardiology, University of Texas McGovern Medical School, Houston, Texas, USA

${ }^{5}$ Epidemiology, University of Pittsburgh, Pittsburgh, Pennsylvania, USA

${ }^{6}$ Ultrasound Research Laboratory, University of Pittsburgh Medical Center,

Pittsburgh, Pennsylvania, USA

${ }^{7}$ Graduate School of Public Health, University of Pittsburgh, Pittsburgh, Pennsylvania, USA

Acknowledgements We would like to thank the study participants, the SOLVABLE research staff at Northwestern University, and the carotid ultrasound technicians, Bonnie Kane, BS, RDCS, and Beverly Smulevitz, BS.

Contributors All authors were involved in drafting the article or revising it critically for important intellectual content, and all authors approved the final version of the manuscript. AL, AD, WP, DM, TT, EB-M and RR-G were responsible for study conception and design. AL, KS-T, EB-M and RR-G were responsible for acquisition of data. JS, PWW, JL and RR-G were responsible for analysis and interpretation of data.

Funding This work was supported by the National Institutes of Health (T32AR07611, P60-AR30692, P60-AR48098, 8UL1TR000150, P60-AR064464, P30AR072579); Mary Kirkland Scholars Award; Pfizer Clinical Rheumatology Fellowship Award; the Solovy Arthritis Research Society; and Nancy and Marvin Himmelstein through the Jack and Shirley DuBow Charitable Foundation.

Competing interests AL is currently employed by Boehringer Ingelheim. The remaining authors declare no competing interests.

Patient and public involvement Patients and/or the public were not involved in the design, or conduct, or reporting, or dissemination plans of this research. Patient consent for publication Not required.

Ethics approval Protocols were approved by the Institutional Review Board of Northwestern University (ID: STU00009196-CR0002).

Provenance and peer review Not commissioned; externally peer reviewed. Data availability statement Data are available upon reasonable request. Additional supplemental data are available upon request.

Open access This is an open access article distributed in accordance with the Creative Commons Attribution Non Commercial (CC BY-NC 4.0) license, which permits others to distribute, remix, adapt, build upon this work non-commercially, and license their derivative works on different terms, provided the original work is properly cited, appropriate credit is given, any changes made indicated, and the use is non-commercial. See: http://creativecommons.org/licenses/by-nc/4.0/.

\section{ORCID iD}

Julia Sun http://orcid.org/0000-0002-7807-5307

\section{REFERENCES}

1 Ward MM. Premature morbidity from cardiovascular and cerebrovascular diseases in women with systemic lupus erythematosus. Arthritis Rheum 1999;42:338-46.

2 Urowitz MB, Ibañez D, Gladman DD. Atherosclerotic vascular events in a single large lupus cohort: prevalence and risk factors. $J$ Rheumatol 2007;34:70-5.

3 Magder LS, Petri M. Incidence of and risk factors for adverse cardiovascular events among patients with systemic lupus erythematosus. Am J Epidemiol 2012;176:708-19.

4 Manzi S, Meilahn EN, Rairie JE, et al. Age-Specific incidence rates of myocardial infarction and angina in women with systemic lupus erythematosus: comparison with the Framingham study. Am J Epidemiol 1997;145:408-15.

5 de Leeuw K, Freire B, Smit AJ, et al. Traditional and non-traditional risk factors contribute to the development of accelerated atherosclerosis in patients with systemic lupus erythematosus. Lupus 2006;15:675-82.

6 Colombo BM, Murdaca G, Caiti M, et al. Intima-Media thickness: a marker of accelerated atherosclerosis in women with systemic lupus erythematosus. Ann N Y Acad Sci 2007;1108:121-6.

7 Roldan CA, Joson J, Sharrar J, et al. Premature aortic atherosclerosis in systemic lupus erythematosus: a controlled transesophageal echocardiographic study. J Rheumatol 2010;37:71-8.

8 Roman MJ, Shanker B-A, Davis A, et al. Prevalence and correlates of accelerated atherosclerosis in systemic lupus erythematosus. N Engl J Med 2003;349:2399-406.

9 Kao AH, Lertratanakul A, Elliott JR, et al. Relation of carotid intima-media thickness and plaque with incident cardiovascular events in women with systemic lupus erythematosus. Am J Cardiol 2013;112:1025-32.

10 de Leeuw K, Smit AJ, de Groot E, et al. Longitudinal study on premature atherosclerosis in patients with systemic lupus erythematosus. Atherosclerosis 2009;206:546-50.

11 Rua-Figueroa I, Arencibia-Mireles O, Elvira M, et al. Factors involved in the progress of preclinical atherosclerosis associated with systemic lupus erythematosus: a 2-year longitudinal study. Ann Rheum Dis 2010;69:1136-9.

12 Telles RW, Lanna CCD, Sousa AJ, et al. Progression of carotid atherosclerosis in patients with systemic lupus erythematosus. Clin Rheumatol 2013;32:1293-300.

13 Thompson T, Sutton-Tyrrell K, Wildman RP, et al. Progression of carotid intima-media thickness and plaque in women with systemic lupus erythematosus. Arthritis Rheum 2008;58:835-42.

14 Kiani AN, Post WS, Magder LS, et al. Predictors of progression in atherosclerosis over 2 years in systemic lupus erythematosus. Rheumatology 2011;50:2071-9.

15 Jorge A, Lertratanakul A, Lee J. Depression and Progression of Subclinical Cardiovascular Disease in Systemic Lupus Erythematosus. Arthritis Care Res (Hoboken) 2017;69(1):5-11. Erratum: Arthritis Care Res 2021;73:1012.

16 McMahon M, Skaggs BJ, Grossman JM, et al. A panel of biomarkers is associated with increased risk of the presence and progression of atherosclerosis in women with systemic lupus erythematosus. Arthritis Rheumatol 2014;66:130-9.

17 Roman MJ, Crow MK, Lockshin MD, et al. Rate and determinants of progression of atherosclerosis in systemic lupus erythematosus. Arthritis Rheum 2007;56:3412-9.

18 Kravvariti E, Konstantonis G, Sfikakis PP, et al. Progression of subclinical atherosclerosis in systemic lupus erythematosus versus rheumatoid arthritis: the impact of low disease activity. Rheumatology 2018;57:2158-66.

19 Wu PW, Rhew EY, Dyer AR, et al. 25-Hydroxyvitamin D and cardiovascular risk factors in women with systemic lupus erythematosus. Arthritis Rheum 2009;61:1387-95.

20 Gladman DD, Ibañez D, Urowitz MB. Systemic lupus erythematosus disease activity index 2000. J Rheumatol 2002;29:288-91.

21 Hochberg MC. Updating the American College of rheumatology revised criteria for the classification of systemic lupus erythematosus. Arthritis Rheum 1997;40:1725.

22 Tan EM, Cohen AS, Fries JF, et al. The 1982 revised criteria for the classification of systemic lupus erythematosus. Arthritis Rheum 1982;25:1271-7.

23 Manzi S, Selzer F, Sutton-Tyrrell K, et al. Prevalence and risk factors of carotid plaque in women with systemic lupus erythematosus. Arthritis Rheum 1999;42:51-60.

24 Sutton-Tyrrell K, Wolfson SK, Thompson T, et al. Measurement variability in duplex scan assessment of carotid atherosclerosis. Stroke 1992;23:215-20. 
25 Doria A, Shoenfeld Y, Wu R, et al. Risk factors for subclinical atherosclerosis in a prospective cohort of patients with systemic lupus erythematosus. Ann Rheum Dis 2003;62:1071-7.

26 Ajeganova S, Gustafsson T, Lindberg L, et al. Similar progression of carotid intima-media thickness in 7-year surveillance of patients with mild SLE and controls, but this progression is still promoted by dyslipidaemia, lower HDL levels, hypertension, history of lupus nephritis and a higher prednisolone usage in patients. Lupus Sci Med 2020;7:e000362.

27 Sutton-Tyrrell K, Lassila HC, Meilahn E, et al. Carotid atherosclerosis in premenopausal and postmenopausal women and its association with risk factors measured after menopause. Stroke 1998;29:1116-21.

28 Karim R, Hodis HN, Detrano R, et al. Relation of Framingham risk score to subclinical atherosclerosis evaluated across three arterial sites. Am J Cardiol 2008;102:825-30.

29 Den Ruijter HM, Peters SAE, Anderson TJ, et al. Common carotid intima-media thickness measurements in cardiovascular risk prediction: a meta-analysis. JAMA 2012;308:796-803.

30 Lorenz MW, Polak JF, Kavousi M, et al. Carotid intima-media thickness progression to predict cardiovascular events in the genera population (the PROG-IMT collaborative project): a meta-analysis of individual participant data. Lancet 2012;379:2053-62.

31 Polak JF, Pencina MJ, O'Leary DH, et al. Common carotid artery intima-media thickness progression as a predictor of stroke in multiethnic study of atherosclerosis. Stroke 2011;42:3017-21.

32 Oryoji K, Kiyohara C, Horiuchi T, et al. Reduced carotid intima-media thickness in systemic lupus erythematosus patients treated with cyclosporine a. Mod Rheumatol 2014;24:86-92.

33 Floris A, Piga M, Mangoni AA, et al. Protective effects of hydroxychloroquine against accelerated atherosclerosis in systemic lupus erythematosus. Mediators Inflamm 2018;2018:1-11.

34 Yang D-H, Leong P-Y, Sia S-K, et al. Long-Term hydroxychloroquine therapy and risk of coronary artery disease in patients with systemic lupus erythematosus. J Clin Med 2019;8:796.
35 Selzer F, Sutton-Tyrrell K, Fitzgerald S, et al. Vascular stiffness in women with systemic lupus erythematosus. Hypertension 2001;37:1075-82.

36 Tanay A, Leibovitz E, Frayman A, et al. Vascular elasticity of systemic lupus erythematosus patients is associated with steroids and hydroxychloroquine treatment. Ann N Y Acad Sci 2007;1108:24-34.

37 Ammirati E, Bozzolo EP, Contri R, et al. Cardiometabolic and immune factors associated with increased common carotid artery intima-media thickness and cardiovascular disease in patients with systemic lupus erythematosus. Nutr Metab Cardiovasc Dis 2014;24:751-9.

38 Gheita TA, Raafat HA, Sayed S, et al. Metabolic syndrome and insulin resistance comorbidity in systemic lupus erythematosus. Effect on carotid intima-media thickness. Z Rheumatol 2013;72:172-7.

39 Sánchez-Pérez H, Tejera-Segura B, de Vera-González A, et al. Insulin resistance in systemic lupus erythematosus patients: contributing factors and relationship with subclinical atherosclerosis. Clin Exp Rheumatol 2017;35:885-92.

40 Green D, Foiles N, Chan C, et al. Elevated fibrinogen levels and subsequent subclinical atherosclerosis: the cardia study. Atherosclerosis 2009;202:623-31.

41 AlMuhanna K, Hossain MM, Zhao L, et al. Carotid plaque morphometric assessment with three-dimensional ultrasound imaging. J Vasc Surg 2015;61:690-7.

42 Bar M, Roubec M, Farana R, et al. Inter-Rater reliability of carotid atherosclerotic plaque quantification by 3-dimensional sonography. $J$ Ultrasound Med 2014;33:1273-8.

43 Parker B, Urowitz MB, Gladman DD, et al. Clinical associations of the metabolic syndrome in systemic lupus erythematosus: data from an international inception cohort. Ann Rheum Dis 2013;72:1308-14.

44 Espeland MA, Evans GW, Wagenknecht LE, et al. SiteSpecific progression of carotid artery intimal-medial thickness. Atherosclerosis 2003;171:137-43.

45 Watase $\mathrm{H}$, Sun J, Hippe DS, et al. Carotid artery remodeling is segment specific. Arterioscler Thromb Vasc Biol 2018;38:927-34. 